\title{
Unconfined Compressive Strength of Aqueous Polymer-Modified Saline Soil
}

\author{
Yan Zhu $\mathbb{D}^{1,2}$ Xiangjuan Yu ${ }^{1},{ }^{1}$ Lei Gao, ${ }^{1}$ Jiajia Chen, ${ }^{3}$ and Michael Dino Cotugno ${ }^{4}$ \\ ${ }^{1}$ College of Civil and Transportation Engineering, Hohai University, Nanjing 210098, China \\ ${ }^{2}$ Department of Architectural Engineering, Nantong Vocational University, Nantong 226007, China \\ ${ }^{3}$ Jiangsu Nantong Liujian Construction Group Co., Ltd., Nantong 226500, China \\ ${ }^{4}$ Dawson College, Montreal, QC, Canada \\ Correspondence should be addressed to Xiangjuan Yu; xjyu@hhu.edu.cn
}

Received 15 March 2019; Revised 15 July 2019; Accepted 6 August 2019; Published 5 November 2019

Academic Editor: Ulrich Maschke

Copyright ( 2019 Yan Zhu et al. This is an open access article distributed under the Creative Commons Attribution License, which permits unrestricted use, distribution, and reproduction in any medium, provided the original work is properly cited.

\begin{abstract}
Saline soil is a special soil that consists of fine particles and has poor engineering properties. It causes salt heaving and is collapsible and corrosive. The treatment of this type of soil for the use as a resource for roadbed fillings has been one of the most important engineering topics in highway construction near coastal areas. This study introduces a new type of aqueous polymer, called ZM, which is used to amend and stabilize saline soil. To test the effects of ZM-solidified saline soil, unconfined compressive strength (UCS) tests were carried out on unmodified and ZM-modified saline soil specimens, respectively. The test results show that the ZM additive significantly improves the UCS. Based on the increase of the ZM admixture, the UCS increases with the curing time. The main increment of the UCS occurs within the first seven days of curing. In addition, the salt content has a great influence on the UCS. With increasing ZM concentration and curing time, the water stability and wetting-drying cycling resistance improve. Based on the X-ray diffraction results, the diffraction peaks of ZM-modified saline soil insignificantly change compared with those of unmodified saline soil. However, the SEM images indicate the formation of membrane structures in ZM-modified saline soil. The modification process produces denser and more stable soil because the reaction products fill voids inside the soil and form a viscous membrane structure on the soil surface.
\end{abstract}

\section{Introduction}

Geological formations in coastal areas are relatively new. The effects of seawater leaching and coastal degeneration lead to a high degree of mineralization of groundwater bodies. When the groundwater rises along the capillary of the soil layer to the surface or close to the surface, the salt in the water is separated by evaporation and condenses on the surface or in the subsurface soil and coastal saline soil is formed. Most of the coastal salinized soil is chlorine salinized soil. Chlorine salt causes undesirable geological problems-such as uneven settlement, salt heaving, pavement grouting, and frost heaving. These problems affect road engineering and hinder the development of the local economy $[1,2]$.

Various methods have been used to improve the physical and engineering properties of saline soil: physical, chemical, biological, mechanical, and electrical methods [3-6]. Among these methods, chemical additives for soil stabilization have recently received attention. There are two types of soil stabilizers: inorganic stabilizers and organic polymer stabilizers. Inorganic stabilizers, including cement [7-10], fly ash [11-13], lime $[14,15]$, and fibers [16-19], are mainly used in roadbeds, foundations, piles, and embankments. They greatly improve the strength and stiffness of the soil, but their durability and environmental effects remain unknown and need to be studied. Hence, a new type of soil stabilizers, that is, organic polymer soil additives, has been developed and applied in many countries during the last two decades [20-28]. Many types of organic polymers as soil stabilizers have been studied systematically by laboratory and field tests [26, 29-33]. The polymer stabilizers have been used to improve the soil to meet engineering requirements for desert land restoration, 
forest roads, and boreholes. The water resistance, unconfined compressive strength, and flexural strength of soil can be improved by polymer stabilizers. In addition, the Atterberg limits, expansion potential, and expansion pressure of polymer-modified soil are all significantly reduced. The results of these studies show that aqueous polymer stabilizers can improve the strength properties of soil.

A new aqueous polymer soil stabilizer is introduced in this paper. This stabilizer was developed at Hohai University to modify saline soil and is called ZM. To test the effect of ZM-solidified saline soil, unconfined compressive strength (UCS) tests were carried out on unmodified and ZMmodified saline soil specimens. The solidification mechanism of ZM-modified saline soil is discussed.

\section{Materials}

2.1. Soil Characteristics. Saline soil is widely available and used in many geotechnical projects. Therefore, it has been chosen as the object of this study. Nonsaline soil was used in this research to create saline soil specimens with different salt contents. It was obtained from a depth of $2 \mathrm{~m}$ below the ground surface of Nantong City in Jiangsu, China. Table 1 shows the engineering characteristics of the soil.

2.2. Synthesis and Characteristics of ZM. ZM soil stabilizer is white emulsion. Its main reagents include methyl methacrylate (MMA), butyl acrylate (BA), ammonium persulfate (APS), sodium dodecyl sulfate (SDS), alkyl phenol polyoxyethylene ether (OP-10), and deionized water $\left(\mathrm{H}_{2} \mathrm{O}\right)$. The $\mathrm{ZM}$ was synthesized in a three-port flask containing a blender, a thermometer, and a condenser tube. First, $50 \mathrm{ml}$ $\mathrm{H}_{2} \mathrm{O}$ and $\mathrm{OP}-10$ were added to the flask. The mix was stirred in warm water until it is completely dissolved and then cooled to room temperature. The APS was added to the flask and completely dissolved. Subsequently, $20 \mathrm{ml} \mathrm{H}_{2} \mathrm{O}$ was used to flush the SDS from the flask wall back into the flask. Afterwards, MMA and BA were added to the flask and mixed under continuous stirring. Meanwhile, the water bath pot was heated. The chemical reaction occurred when the pot reached a temperature of $80^{\circ}-85^{\circ} \mathrm{C}$. The pot was heated for 3 to $4 \mathrm{~h}$ until liquid reflux was observed. Because the reflux weakened, the pot was heated up to $85^{\circ} \mathrm{C}$ for another half hour. The reaction was then complete, and specimens were obtained at room temperature. The chemical equation for the polymerization reaction of ZM is shown in Figure 1.

The main component of ZM is acrylate polymer (Figure 1), which contains a large number of functional groups $-\mathrm{COOH}$ and $-\mathrm{OH}$. Its molecular weight is in the range of $11000-15000(\mathrm{~g} / \mathrm{mol})$, and the average degree of polymerization is 500-700. The molar ratio of each monomer of ZM is detailed in patent 201810986971.6 (in Chinese). Table 2 shows the important physicochemical characteristics of ZM. As a new type of soil modifier applied to coastal saline soil, ZM has significant advantages: (i) it has a wide range of raw materials, simple synthetic process, and low cost; (ii) it is an aqueous polymer material which can be configured to different proportions; (iii) gel-like bonding compounds can be formed, which cover the soil surface and fill voids inside the soil under natural conditions.

\section{Sample Preparation}

In this experiment, artificial saline soil was prepared. The soil specimens were oven-dried and screened to aggregate sizes of less than $2 \mathrm{~mm}$ in diameter. After 24 hours at room temperature, soil specimens with the specific water content were prepared. Depending on the required salt content, $\mathrm{NaCl}$ solution was mixed with the soil and sealed at room temperature for seven days to allow for an even salt distribution and uniform exchange with the soil. Over the next $48 \mathrm{~h}$, enough distilled water was added to maintain the exchange absorption between the soil specimens and salt. Finally, the soil was dried, crushed, and screened $(2 \mathrm{~mm})$ to obtain an artificially prepared saline soil.

The screened saline soil was mixed with six different concentrations of ZM emulsion by total dry weight of soil: $0 \%$, $0.3 \%, 0.6 \%, 0.9 \%, 1.2 \%$, and $1.5 \%$. Standard proctor compaction tests were carried out on various saline soil-ZM mixtures in accordance with ASTM D698-12e2 [34]. The results are provided in Table 3 . The specimens were prepared by static compaction at their respective optimum moisture contents and maximum dry unit weight values. Four-layered compaction was used for UCS tests to maintain the uniformity of the specimens with a diameter of $39.1 \mathrm{~mm}$ and a height of $80 \mathrm{~mm}$. After preparing the specimens, the specimens were separately tested after $0,7,14,21$, and 28 days of storage in a standard container at a temperature of $25^{\circ} \mathrm{C}$ and humidity of $95 \%$.

\section{Test Methods}

4.1. Unconfined Compressive Strength Test. The influence of ZM-stabilized saline soil on the compressive strength was investigated using the UCS index in accordance with the ASTM D2166/ASTM D2166M-16 standard [35]. Tests were performed at a loading speed of $2.4 \mathrm{~mm} / \mathrm{min}$ until the specimens failed. Additionally, UCS tests were carried out for each group of three replicates. The test results represent the average values of the tests. The soil samples were prepared with the same method as that used for the UCS tests, as shown in Table 3.

4.2. Water Stability Test. One group of the specimens was immersed in water for $24 \mathrm{~h}$ before reaching the 7 and 28 days of cure times; subsequently, the UCS was determined to obtain the immersion strength $\left(q_{\mathrm{ui}}\right)$. The UCS of the control specimens $\left(q_{\mathrm{u} 0}\right)$ selected the sample strength of 7 and 28 days in Table 3 . The ratio between $q_{\mathrm{ui}}$ and $q_{\mathrm{u} 0}$ was equivalent to the water stability coefficient $K$, as shown in

$$
K=\frac{q_{\mathrm{ui}}}{q_{\mathrm{u} 0}} \times 100 \% .
$$

4.3. Wetting-Drying Circling Test. Wetting-drying cycle meant that the specimens are immersed in water for $12 \mathrm{~h}$ and then naturally dried at an ordinary condition for $12 \mathrm{~h}$. 
TABLE 1: Soil characteristics.

\begin{tabular}{lccccccccc}
\hline Serial & Specific & Sand & Gran size & Atterberg limits & \multicolumn{3}{c}{ Compaction parameters } \\
number & gravity & $\begin{array}{c}\text { Silt } \\
(0 / 075-2 \mathrm{~mm}) \\
(\%)\end{array}$ & $\begin{array}{c}\text { Clay } \\
(\%) \mu \mathrm{m}) \\
(\%)\end{array}$ & $\begin{array}{c}\text { Liquid } \\
(\%)\end{array}$ & $\begin{array}{c}\text { Plastic } \\
\text { limits }(\%)\end{array}$ & $\begin{array}{c}\text { Plasticity } \\
\text { limits }(\%)\end{array}$ & $\begin{array}{c}\text { Optimum } \\
\text { index }(\%)\end{array}$ & $\begin{array}{c}\text { Mater } \\
\text { content }(\%)\end{array}$ & $\begin{array}{c}\text { dry unit weight } \\
\left(\mathrm{g} / \mathrm{cm}^{3}\right)\end{array}$ \\
\hline 1 & 2.61 & 2.42 & 85.31 & 12.27 & 22.1 & 10.4 & 11.7 & 18.3 \\
\hline
\end{tabular}

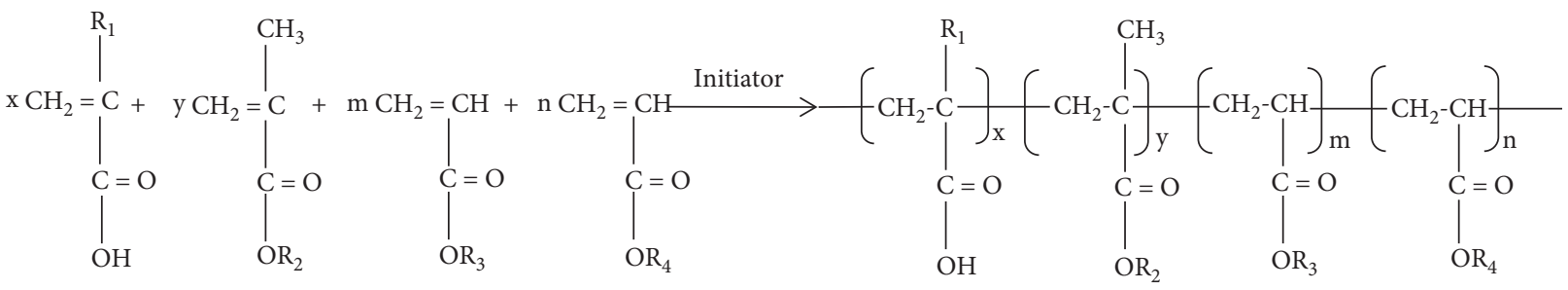

$\mathrm{R}_{1}=\mathrm{H}, \mathrm{CH}_{3} \quad \mathrm{R}_{2}=\mathrm{CH}_{3}, \mathrm{C}_{2} \mathrm{H}_{5}, \mathrm{C}_{4} \mathrm{H}_{9}, \mathrm{C}_{8} \mathrm{H}_{17}, \mathrm{C}_{18} \mathrm{H}_{37} \quad \mathrm{R}_{3}=\mathrm{CH}_{3}, \mathrm{C}_{2} \mathrm{H}_{5}, \mathrm{C}_{4} \mathrm{H}_{9}, \mathrm{C}_{8} \mathrm{H}_{17} \quad \mathrm{R}_{4}=\mathrm{C}_{2} \mathrm{H}_{5} \mathrm{OH}, \mathrm{C}_{3} \mathrm{H}_{7} \mathrm{OH}, \mathrm{C}_{4} \mathrm{H}_{9} \mathrm{OH}$

Figure 1: Polymerization reaction of ZM.

TABLe 2: Physicochemical characteristics of ZM.

\begin{tabular}{lc}
\hline Physicochemical properties & Values \\
\hline $\mathrm{pH}$ & $6-7$ \\
Phase & Liquid \\
Solvability in water & Solution \\
Viscosity (cp) & 290 \\
Specific gravity & 1.06 \\
Solid content & $28 \%$ \\
Color & Opalescent \\
\hline
\end{tabular}

One group of the specimens was tested for one wettingdrying cycle before reaching 7 and 28 days of cure times. Then the UCS of the specimens $\left(q_{\mathrm{uw}}\right)$ was determined. The UCS of the control specimens $\left(q_{\mathrm{u} 0}\right)$ also selected the sample strength of 7 and 28 days in Table 3 . The strength loss rate $G$ of the specimens after 1 wetting-drying cycle was calculated using

$$
G=\frac{q_{\mathrm{u} 0}-q_{\mathrm{uw}}}{q_{\mathrm{u} 0}} \times 100 \% .
$$

\section{Results and Discussions}

5.1. Effect of the ZM Concentration on the UCS. The compressive strength and compressive strain of all tested saline soil specimens ( $3 \%$ salt content, by weight of dry soil) after different curing times are shown in Figure 2; the ZM concentrations were $0 \%, 0.3 \%, 0.6 \%, 0.9 \%, 1.2 \%$, and $1.5 \%$, respectively. To compare the effect of $\mathrm{ZM}$ additives, the compressive strength and compressive strain of specimens without $\mathrm{ZM}$ and those with $0.3 \%-1.5 \% \mathrm{ZM}$ are plotted in each figure. The figures show that the $\mathrm{ZM}$ additives increase the sample UCS. Figures 2(a)-2(e) show the compressive strength and compressive strain of the specimens after a curing time of $0,7,14,21$, and 28 days, respectively. The maximum compressive strength was observed in the case of $1.5 \%$
$\mathrm{ZM}$ after a curing period of seven days. In this case, the compressive strength increased from $700 \mathrm{kPa}$ for specimens without $\mathrm{ZM}$ to $1561 \mathrm{kPa}$. The compressive strength of the specimens with ZM concentrations of less than $1.5 \%$, that is, $0.3 \%, 0.6 \%, 0.9 \%$, and $1.2 \%$, is $1085,1164,1230$, and $1317 \mathrm{kPa}$, respectively. Based on the ASTM D4609-08 standard [36], a minimum compressive strength increase of $345 \mathrm{kPa}$ is a criterion for an effective stabilization. Specimens with ZM concentrations of $0.3 \%-1.5 \%$ meet this criterion and thus are classified as effective stabilization scenarios. In addition, the compressive strength and compressive strain of both the unmodified and ZM-modified specimens show a strain-softening behavior. Ductile failure can be observed. Compared with the unmodified specimens, ZM-modified specimens maintain a high residual strength after reaching the peak strength at different curing times.

The UCS values for different ZM concentrations and different curing times are presented in Table 3 and Figure 3. The strength characteristics of the saline soil are notably enhanced by the ZM soil stabilizer. The strength gradually increases as the ZM concentration increases from $0.3 \%$ to $1.5 \%$ and as the curing time increases from 7 to 28 days. However, the strength of the uncured specimens is rather stable. The modified specimens have a higher strength than the unmodified specimens after curing. The maximum strength of $1930 \mathrm{kPa}$ was obtained at a $\mathrm{ZM}$ concentration of $1.5 \%$ after 28 days of curing. It is 2.05 times larger than that of the unmodified specimens after a curing time of 28 days and 2.51 times higher than that of specimens with a ZM concentration of $1.5 \%$ without curing. This is because chemical reactions between $\mathrm{ZM}$ and soil components form a kind of viscous membrane structure, which leads to the strength increase of the modified specimens. And these chemical reactions normally occur over a few days.

5.2. Effect of the Salt Content on the UCS. The compressive strength and compressive strain of specimens with saline soil $(0 \%, 0.4 \%, 3 \%, 6 \%$, and $9 \%$, respectively, by weight of dry soil) after a curing period of seven days are shown in 
TABLE 3: Unconfined compressive strength of the specimens.

\begin{tabular}{|c|c|c|c|c|c|c|c|c|}
\hline \multirow{2}{*}{ Serial number } & \multirow{2}{*}{ ZM content $(\%)$} & \multirow{2}{*}{ Water content $(\%)$} & \multirow{2}{*}{ Dry density $\left(\mathrm{g} / \mathrm{cm}^{3}\right)$} & \multicolumn{5}{|c|}{ UCS $(\mathrm{kPa}) /$ standard deviation $(\mathrm{kPa})$} \\
\hline & & & & $0 \mathrm{~d}$ & $7 \mathrm{~d}$ & $14 \mathrm{~d}$ & $21 \mathrm{~d}$ & $28 \mathrm{~d}$ \\
\hline 1 & 0 & 18.3 & 1.56 & $451 / 17.8$ & $700 / 29.9$ & $721 / 32.4$ & $831 / 31.9$ & $942 / 42.3$ \\
\hline 2 & 0.3 & 18.3 & 1.56 & $463 / 20.3$ & $1085 / 28.6$ & $1279 / 51.2$ & $1294 / 50.8$ & $1453 / 56.1$ \\
\hline 3 & 0.6 & 18.3 & 1.56 & $552 / 21.9$ & $1164 / 41.2$ & $1324 / 52.5$ & $1362 / 48.2$ & $1552 / 60.5$ \\
\hline 4 & 0.9 & 18.3 & 1.56 & $561 / 26.3$ & $1230 / 47.1$ & $1328 / 44.3$ & $1389 / 60.8$ & $1616 / 65.4$ \\
\hline 5 & 1.2 & 18.3 & 1.56 & $544 / 22.0$ & $1317 / 47.2$ & $1411 / 45.7$ & $1452 / 52.7$ & $1903 / 51.3$ \\
\hline 6 & 1.5 & 18.3 & 1.56 & $553 / 21.7$ & $1561 / 46.5$ & $1663 / 65.8$ & $1774 / 62.7$ & $1930 / 53.8$ \\
\hline
\end{tabular}

Figure 4. To compare the effects of the different salt contents, the compressive strength and compressive strain of specimens with a salt content ranging from $0 \%$ to $9 \%$ are included in each figure. The UCS of the specimens decreases with increasing salt content. Figures 4(a)-4(f) show the compressive strength and compressive strain of specimens with different ZM concentrations ( $0 \%, 0.3 \%, 0.6 \%, 0.9 \%, 1.2 \%$, and $1.5 \%)$. All specimens show strain-softening ductile failure; the residual strength reduces with increasing salt content at different ZM concentrations.

Figure 5 shows the effect of the salt content on the UCS of specimens with different ZM concentrations after a curing time of seven days. The increase in the salt content reduces the UCS of ZM-modified and unmodified specimens. A salt content of $0.4 \%$ has a smaller effect on the UCS; the strength of the modified specimens is only reduced by $5.4 \%, 3.1 \%$, $6.4 \%, 4.3 \%$, and $5.4 \%$, respectively. However, when the salt content of the soil exceeds $3 \%$, the strength rapidly decreases with increasing salt content. Additionally, the decrease of the UCS is most pronounced for salt contents ranging from $6 \%$ to $9 \%$; it reaches $44.0 \%, 42.0 \%, 41.2 \%, 42.5 \%$, and $34.5 \%$, respectively. Furthermore, the strength of the unmodified specimens also decreases by $34.8 \%$. This indicates that the salt content of the soil has a great influence on the strength of modified saline soil. Hence, the soil should be sampled at any time to ensure the quality of the construction.

5.3. Effect of the Curing Time on the UCS. Figure 6 shows that the UCS of each sample significantly increases with increasing curing time. However, the main increment of the UCS increase occurs within seven days of curing (Figure 7). As an example, the UCS of specimens with $0.3 \%$ ZM reaches $1.09 \mathrm{MPa}$ after seven days of curing (a $0.63 \mathrm{MPa}$ increment) and $1.45 \mathrm{MPa}$ after 28 days of curing (a $0.16 \mathrm{MPa}$ increment over 21 days). The relative UCS increase of soil with $1.5 \%$ $\mathrm{ZM}$ after $7,14,21$, and 28 days is $183.6 \%, 6.4 \%, 6.6 \%$, and $9.0 \%$, respectively. This demonstrates that soil-stabilizing reactions primarily occur in the early stages of curing; thus, special attention should be paid to the premaintenance of projects.

5.4. Water Stability. The specimens with different ZM concentrations and a salt content of 3\% (by weight of dry soil) were tested for water stability. After the immersion for $24 \mathrm{~h}$, unmodified specimens completely collapse; thus, their UCS was not tested. The water stability of unmodified specimens is extremely poor. Specimens with a ZM concentration of
$0.9 \%$ show a peeling phenomenon and specimens with a ZM concentration of $1.5 \%$ maintain their integrity.

Table 4 illustrates the variation of the strength of the specimens with different ZM concentrations after different curing times subjected to water stability. The immersion process adversely affects the strength. Before immersion, soil with $0 \% \mathrm{ZM}$ displays $q_{\mathrm{u} 0}$ values of $700 \mathrm{kPa}$ and $940 \mathrm{kPa}$ after a curing time of 7 and $28 \mathrm{~d}$, respectively. However, the $q_{\mathrm{ui}}$ value of $0 \mathrm{kPa}$ was obtained after 24 -hour immersion. A similar effect was observed for the sample stabilized with $1.5 \%$ $\mathrm{ZM}$, where $q_{\mathrm{u}}$ decreases from $1561 \mathrm{kPa}$ and $1930 \mathrm{kPa}$ to $970 \mathrm{kPa}$ and $1570 \mathrm{kPa}$, respectively.

The water stability index $K$ is presented in Table 4 . The $K$ -value of the specimens increases with the addition of ZM soil stabilizer. The $K$-value of specimens with ZM concentrations of $0.3 \%-1.5 \%$ is approximately $60 \%$ after 7 days, while the $K$-value of the unmodified specimens is zero. In addition, the $K$-value of the specimens also increases with the curing time. The $K$-value of the modified specimens increases by $16.22 \%, 20.95 \%, 21.71 \%, 19.17 \%$, and $19.17 \%$, respectively, between 7 and 28 days of curing and remains approximately $80 \%$ after 28 days. In contrast to the unmodified specimens, the addition of ZM significantly increases the water stability of the specimens.

5.5. Wetting-Drying Cycling Resistance. Specimens with different ZM concentrations and a salt content of 3\% (by weight of dry soil) after a curing time of 28 days were tested for 1 wetting-drying cycle. During the experiment, it is found that the surface of the unmodified specimens has been severely stripped and the specimens are fractured. Although the specimens with a ZM concentration of $0.9 \%$ are not broken, their surface has been eroded. The integrity of specimens with $1.5 \% \mathrm{ZM}$ concentrations is better.

Table 5 illustrates the variation of the strength for specimens with different $\mathrm{ZM}$ concentrations and curing times before and after wetting-drying cycles. The wetting and drying process adversely affects the strength. Before wetting and drying, soil with $0 \% \mathrm{ZM}$ displays $q_{\mathrm{u} 0}$ values of 700 and $942 \mathrm{kPa}$ after 7 and $28 \mathrm{~d}$ of curing, respectively. However, after 1 wetting-drying cycle, a $q_{\text {uw }}$ value of $0 \mathrm{kPa}$ was obtained. A similar effect was observed for the sample stabilized with $1.5 \% \mathrm{ZM}$, where the $q_{\mathrm{u}}$ value decreases from 1561 and $1930 \mathrm{kPa}$ to 890 and $1570 \mathrm{kPa}$, respectively.

The variation of the strength loss rate $G$ depending on the $\mathrm{ZM}$ concentration and curing time is illustrated in Table 5. The $G$-value of the specimens decreases with the addition 


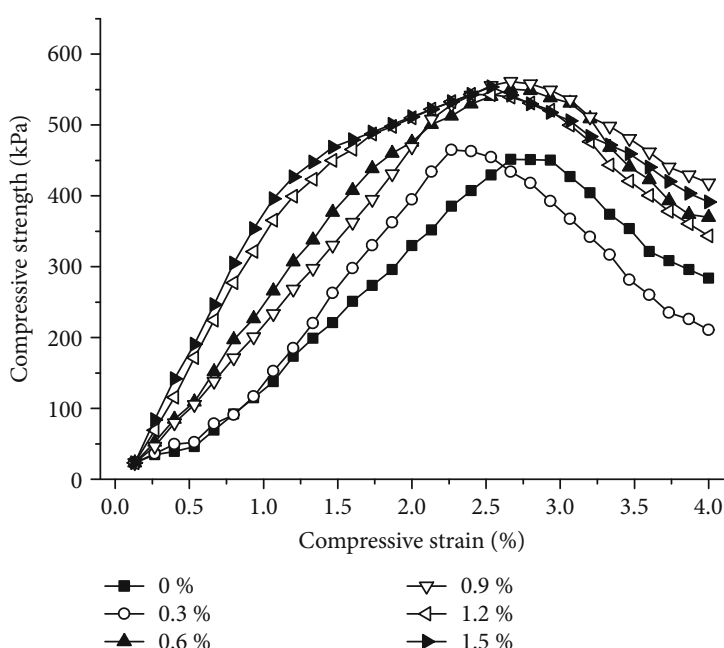

(a)

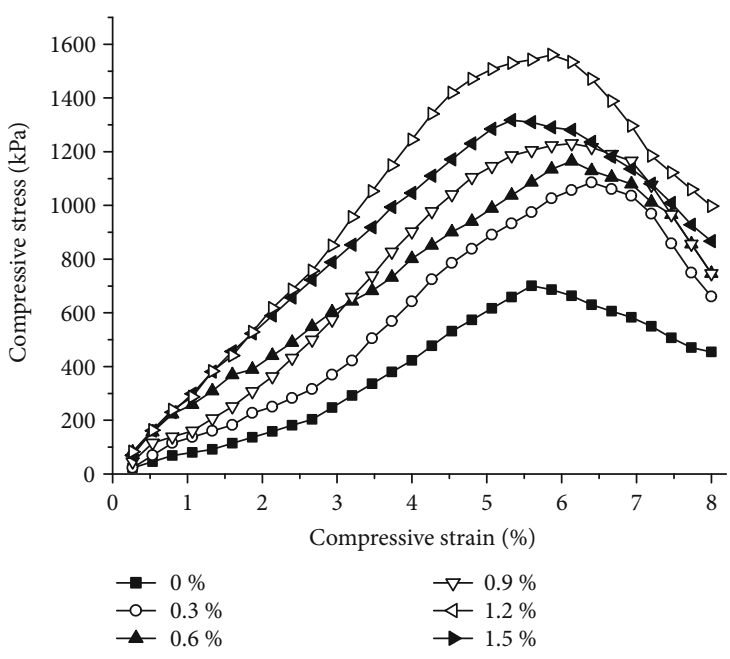

(c)

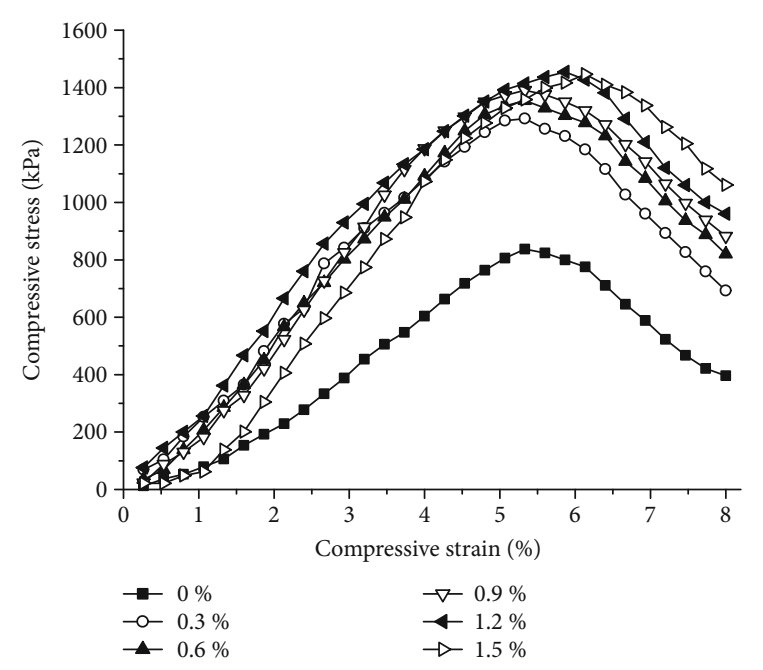

(b)

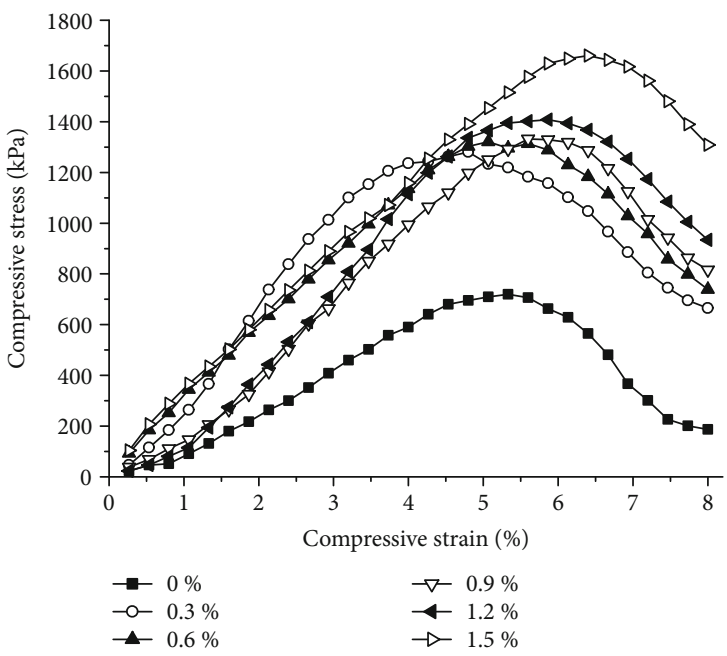

(d)

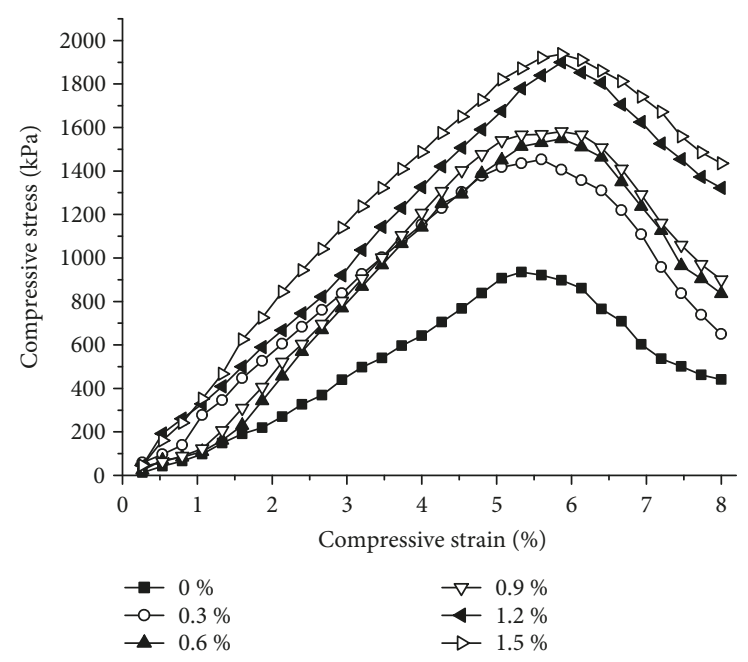

(e)

FIGURE 2: Compressive strength and compressive strain of specimens with different ZM concentrations after a curing time of (a) $0 \mathrm{~d}$, (b) $7 \mathrm{~d}$, (c) $14 \mathrm{~d}$, (d) $21 \mathrm{~d}$, and (e) $28 \mathrm{~d}$. 


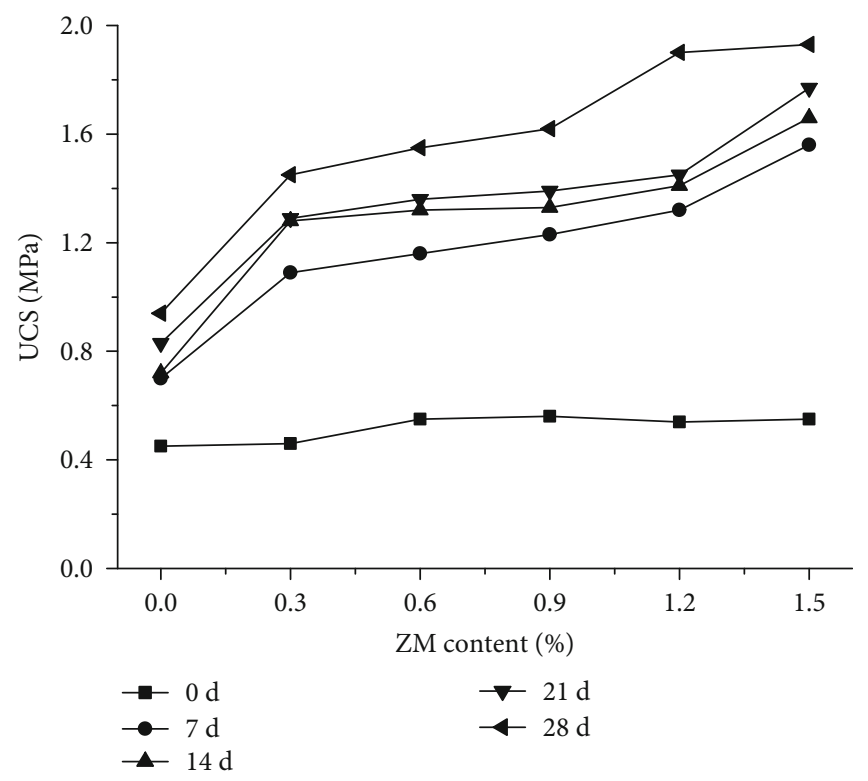

FIgURE 3: Effect of the ZM concentration on the UCS for different curing times.

of ZM soil stabilizer. The strength loss rate $G$ of the specimens modified with ZM concentrations of $0.3 \%, 0.6 \%$, $0.9 \%, 1.2 \%$, and $1.5 \%$ decreases from $47.71 \%$ to $47.41 \%$, $45.53 \%, 44.70 \%$, and $42.95 \%$, respectively (after curing for seven days). However, the unmodified specimens disintegrate after 1 wetting-drying cycle. The $G$-value of the unmodified specimens reaches $100 \%$. Moreover, the strength loss rate decreases with the curing time. The $G$-value of the modified specimens decreases by $25.79 \%, 27.41 \%, 25.78 \%$, $25.75 \%$, and $24.30 \%$, respectively, between 7 and 28 days of curing. These results indicate that the modified specimens have a higher wetting-drying cycling resistance.

5.6. Optimum Concentration. Based on test results presented in Sections 4.1, 4.2, and 4.3, the use of 1.5\% ZM and 7 days of curing time increases the strength (i.e., up to $122.8 \%$ improvement of the UCS) and mitigates the water stability and wetting-drying cycling resistance (i.e., up to $62.18 \%$ and $57.05 \%$ improvement in $K_{7 \mathrm{~d}}$ and $G_{7 \mathrm{~d}}$, respectively). The strength of $1561 \mathrm{kPa}$ was obtained for saline soil with a salt content of $3 \%$ and ZM concentration of $1.5 \%$ after 7 days of curing, which meets the strength standards for grade bases for highways (1500 kPa, according to JTG/T F20-2015, China). Therefore, from the economic point of view, a ZM concentration of $1.5 \%$ is regarded as the optimum concentration for an effective stabilization. When the cost and design requirements are changed, lower concentrations, such as $0.6 \%, 0.9 \%$, and $1.2 \%$, may also be acceptable choices, but attention should be paid to curing.

\section{Solidification Mechanism}

X-ray diffraction and SEM were used in this study to determine the mechanism based on which ZM stabilizes saline soil.
Figure 8 shows the X-ray diffraction results for unmodified specimens and for specimens with a $3 \%$ salt content that were modified with $1.5 \% \mathrm{ZM}$ after 7 days of curing. Figures 8 (a) and 8(b) show that the X-ray diffraction results for the specimens modified with $1.5 \% \mathrm{ZM}$ are in agreement with the results for the unmodified specimens. No new peaks are observed. This means that the ZM does not chemically react with saline soil to produce new functional groups and mineral components, which mainly is due to the fact that a small ZM admixture has no notable effect on the mineral composition of saline soil.

Figure 9 displays the results of the SEM analyses of unmodified saline soil with $3 \%$ salt. As expected, the unmodified sample presents a discontinuous and dispersed porous structure. Figure 10 shows the SEM images of the modified saline soils (3\% salt) with $1.5 \% \mathrm{ZM}$ after a curing time of 7 and 28 days, respectively. After seven days of curing (Figure 10(a)), a new material with gel-like appearance appeared in the soil. This new gel-like material remained on the surface of the soil particles in the form of a viscous membrane structure and filled up the voids in the soil, as can be seen in the soil images after 28 days of curing (Figure 10(b)). This phenomenon is mainly caused by ZM containing acrylate polymer, which has a large number of functional - $\mathrm{COOH}$ and -OH groups and long-chain macromolecules (Figure 1). When ZM is used to modify saline soil, one part of them fills the pores in the saline soil structure and the other part covers the surface of the saline soil particles. The hydrophilic groups $(-\mathrm{COOH}$ and $-\mathrm{OH})$ chemically react with the negative ions of the clay particles and establish complex physical and chemical bonds between the soil particles and soil stabilizer (hydrogen, ionic, electrostatic, dialysis, or Van der Waals bonds). Based on these bonds, long chains of ZM polymer macromolecules cover the surface of the particles to form a viscous membrane structure. Based on filling and enwrapping of ZM, the UCS, water stability, and 


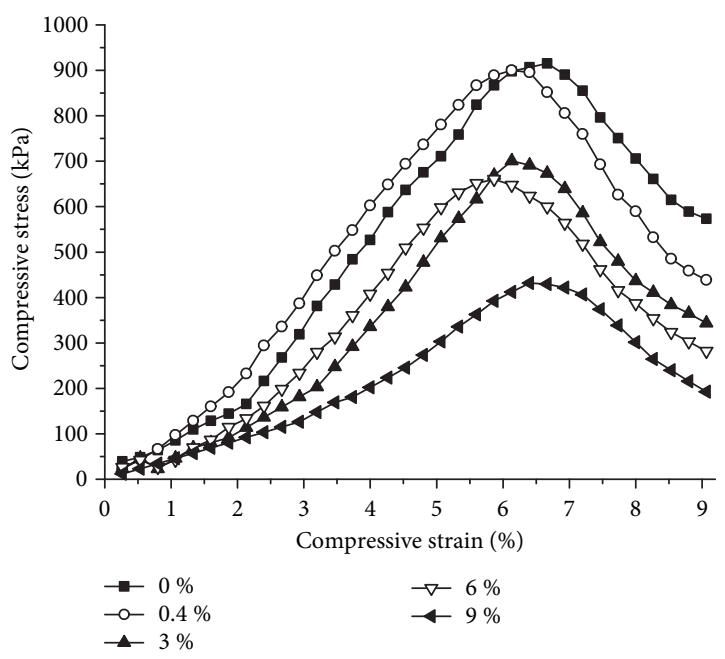

(a)

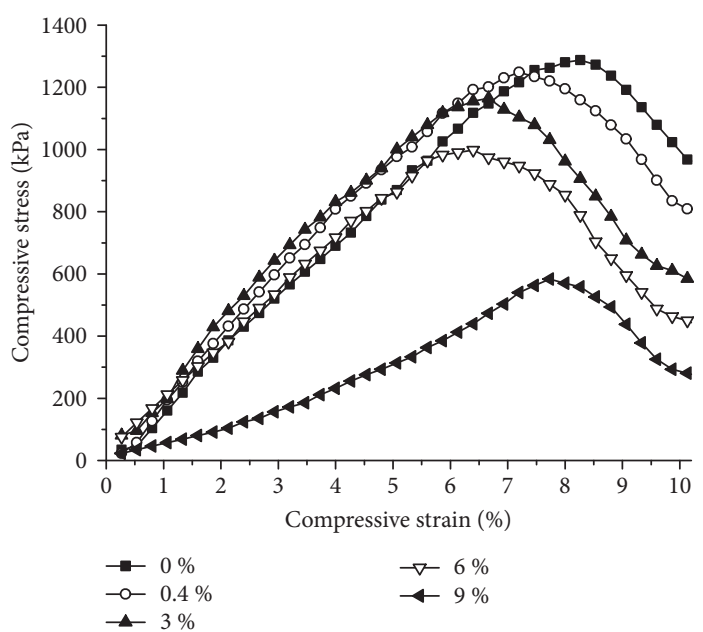

(c)

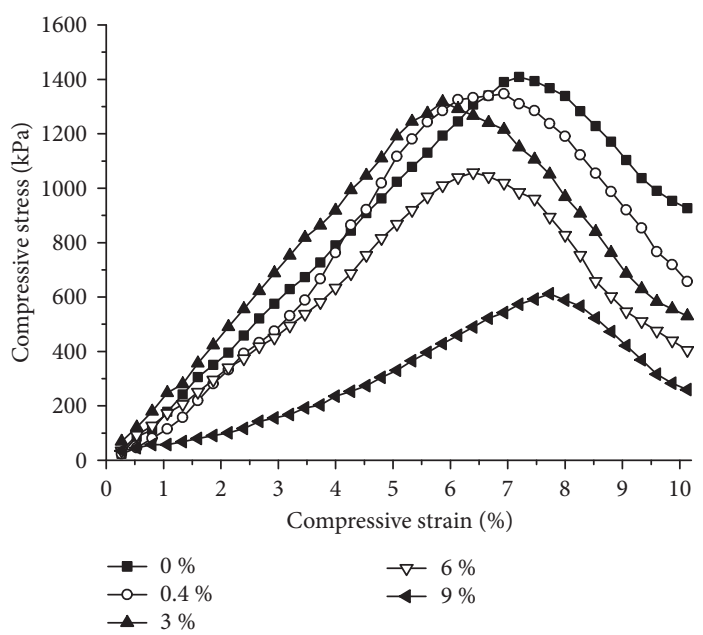

(e)

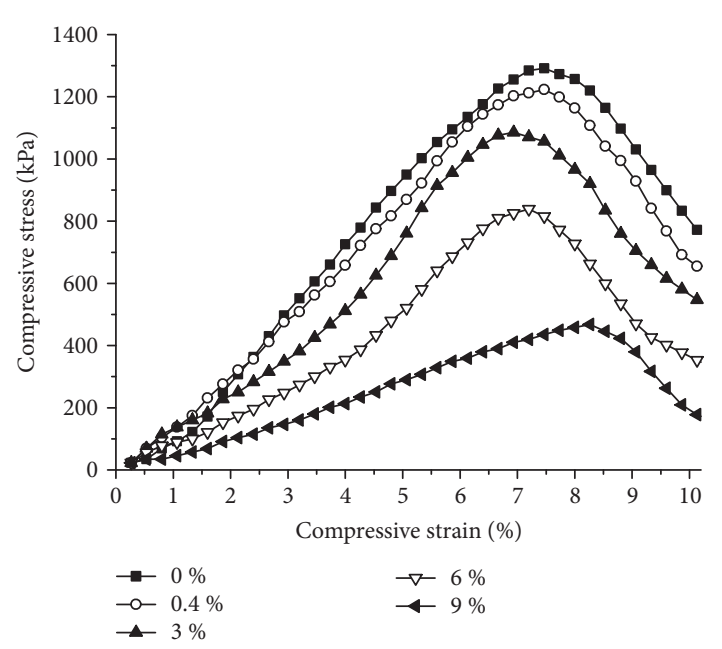

(b)

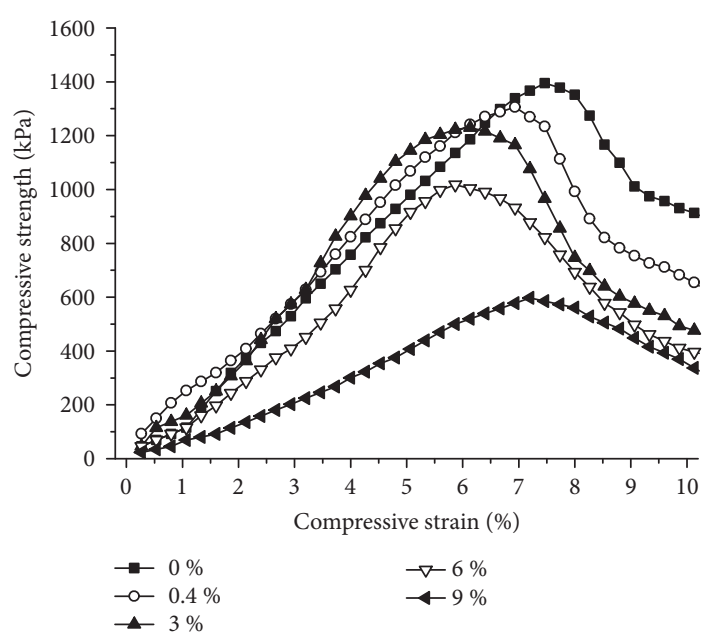

(d)

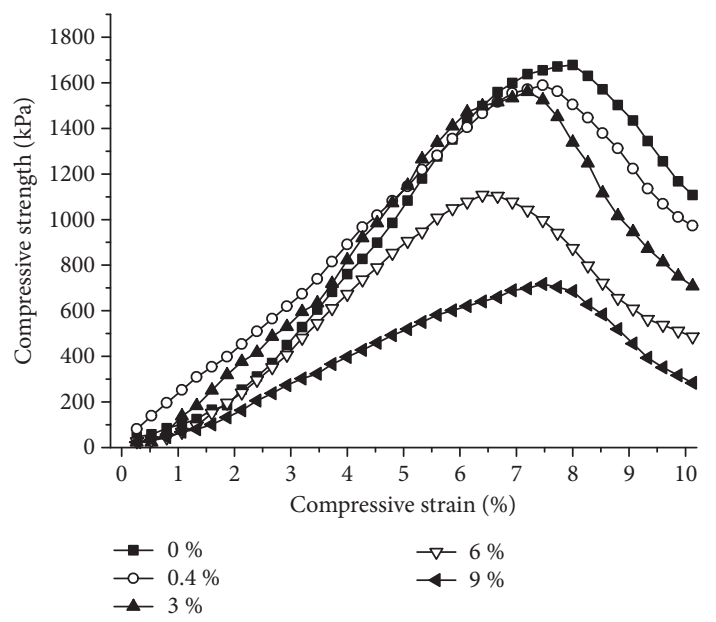

(f)

Figure 4: Compressive strength and compressive strain of specimens with different salt contents after seven days of curing: (a) $0 \% \mathrm{ZM}$, (b) $0.3 \% \mathrm{ZM}$, (c) $0.6 \% \mathrm{ZM}$, (d) $0.9 \% \mathrm{ZM}$, (e) $1.2 \% \mathrm{ZM}$, and (f) $1.5 \% \mathrm{ZM}$. 


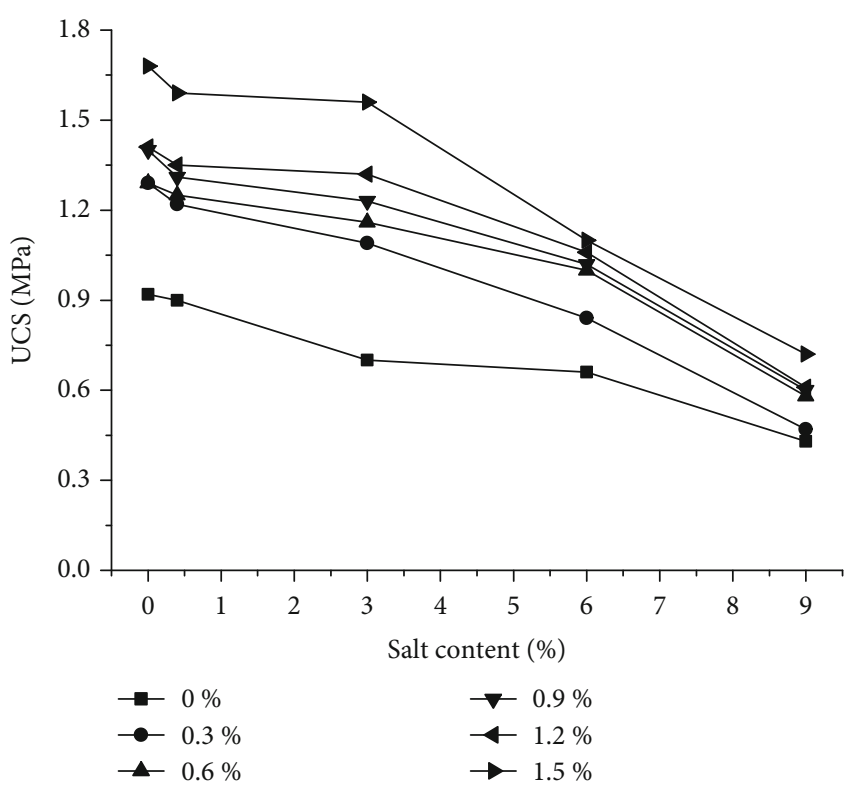

FIGURE 5: Influence of the salt content on the UCS for different ZM concentrations after a curing period of seven days.

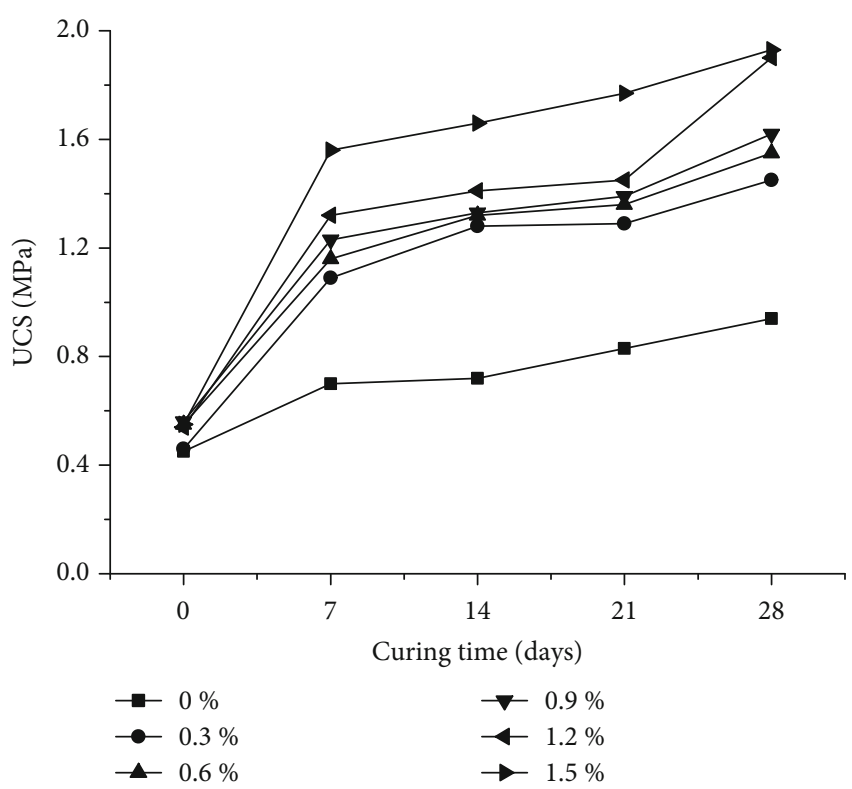

FIGURE 6: Effect of the curing time on the UCS for different ZM concentrations.

wetting-drying cycling resistance of ZM-modified saline soils are improved.

On the other hand, the chemical reactions between the ZM and soil components normally occur over a few days. Hence, the UCS of the solidified soil increases with increasing curing time. However, most of the chemical reactions occur in the early stages of curing such that the UCS quickly increases in the first seven days and then stabilizes (Figure 7). In addition, based on a higher ZM concentration, more porous parts of the soil are filled and

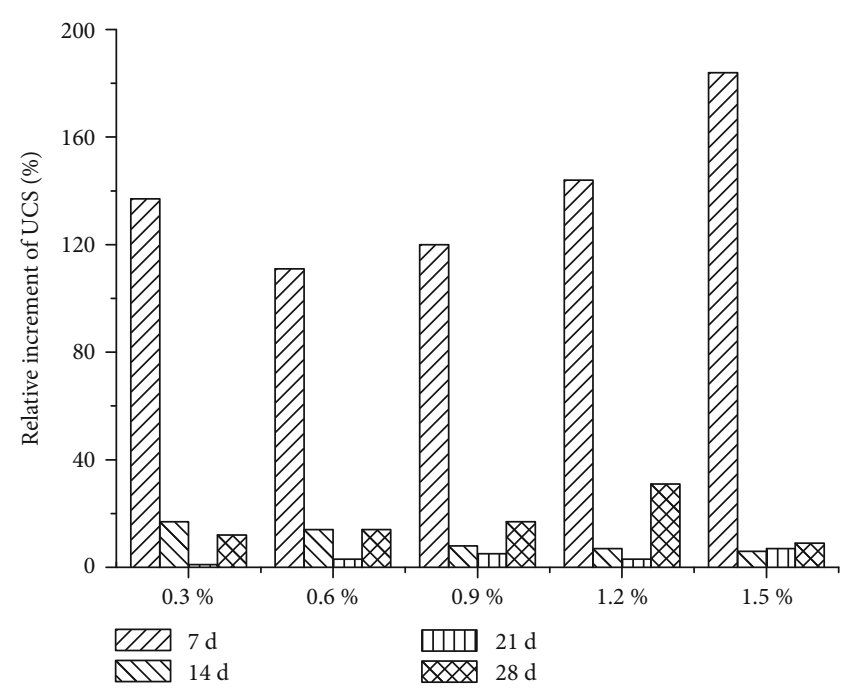

FIgURE 7: Relative increment of the UCS for different ZM concentrations and curing periods.

TABLE 4: Water stability of the specimens after different curing times.

\begin{tabular}{|c|c|c|c|c|c|c|c|}
\hline \multirow{2}{*}{$\begin{array}{l}\text { Serial } \\
\text { number }\end{array}$} & \multirow{2}{*}{$\begin{array}{c}\mathrm{ZM} \\
\text { content } \\
(\%)\end{array}$} & \multicolumn{2}{|c|}{$\begin{array}{l}\text { 7d UCS } \\
(\mathrm{MPa})\end{array}$} & \multicolumn{2}{|c|}{$\begin{array}{c}\text { 28d UCS } \\
(\mathrm{MPa})\end{array}$} & \multicolumn{2}{|c|}{$\begin{array}{c}\text { Water } \\
\text { stability (\%) }\end{array}$} \\
\hline & & $q_{\mathrm{u} 0}$ & $q_{\mathrm{ui}}$ & $q_{\mathrm{u} 0}$ & $q_{\mathrm{ui}}$ & $K_{7 \mathrm{~d}}$ & $K_{28 \mathrm{~d}}$ \\
\hline 1 & 0.0 & 0.70 & 0.00 & 0.94 & 0.00 & 0.00 & 0.00 \\
\hline 2 & 0.3 & 1.09 & 0.62 & 1.45 & 1.06 & 56.88 & 73.10 \\
\hline 3 & 0.6 & 1.16 & 0.67 & 1.55 & 1.22 & 57.76 & 78.71 \\
\hline 4 & 0.9 & 1.23 & 0.72 & 1.62 & 1.30 & 58.54 & 80.25 \\
\hline 5 & 1.2 & 1.32 & 0.81 & 1.90 & 1.53 & 61.36 & 80.53 \\
\hline 6 & 1.5 & 1.56 & 0.97 & 1.93 & 1.57 & 62.18 & 81.35 \\
\hline
\end{tabular}

TABLE 5: One wetting-drying circle of specimens at different curing times.

\begin{tabular}{|c|c|c|c|c|c|c|c|}
\hline \multirow{2}{*}{$\begin{array}{l}\text { Serial } \\
\text { number }\end{array}$} & \multirow{2}{*}{$\begin{array}{c}\mathrm{ZM} \\
\text { content } \\
(\%)\end{array}$} & \multicolumn{2}{|c|}{$\begin{array}{c}7 \mathrm{~d} \mathrm{UCS} \\
(\mathrm{MPa})\end{array}$} & \multicolumn{2}{|c|}{$\begin{array}{c}28 \mathrm{~d} \text { UCS } \\
(\mathrm{MPa})\end{array}$} & \multicolumn{2}{|c|}{$\begin{array}{l}\text { Strength loss } \\
\text { rate }(\%)\end{array}$} \\
\hline & & $q_{\mathrm{u} 0}$ & $q_{\mathrm{uw}}$ & $q_{\mathrm{u} 0}$ & $q_{\mathrm{uw}}$ & $G_{7 \mathrm{~d}}$ & $G_{28 \mathrm{~d}}$ \\
\hline 1 & 0.0 & 0.70 & 0.00 & 0.94 & 0.00 & 100.00 & 100.00 \\
\hline 2 & 0.3 & 1.09 & 0.57 & 1.45 & 1.13 & 47.71 & 21.92 \\
\hline 3 & 0.6 & 1.16 & 0.61 & 1.55 & 1.24 & 47.41 & 20.00 \\
\hline 4 & 0.9 & 1.23 & 0.67 & 1.62 & 1.30 & 45.53 & 19.75 \\
\hline 5 & 1.2 & 1.32 & 0.73 & 1.90 & 1.54 & 44.70 & 18.95 \\
\hline 6 & 1.5 & 1.56 & 0.89 & 1.93 & 1.57 & 42.95 & 18.65 \\
\hline
\end{tabular}

more bonds are formed, leading to greater soil strength (Figures 2 and 3). Therefore, the UCS increases with increasing ZM concentration.

\section{Conclusions}

The purpose of this study was to illustrate the effect of ZM aqueous polymers on saline soil. Based on the laboratory test 


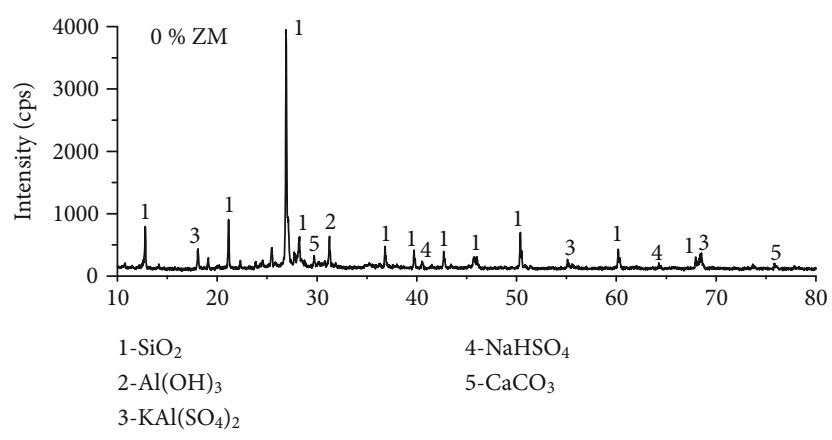

(a)

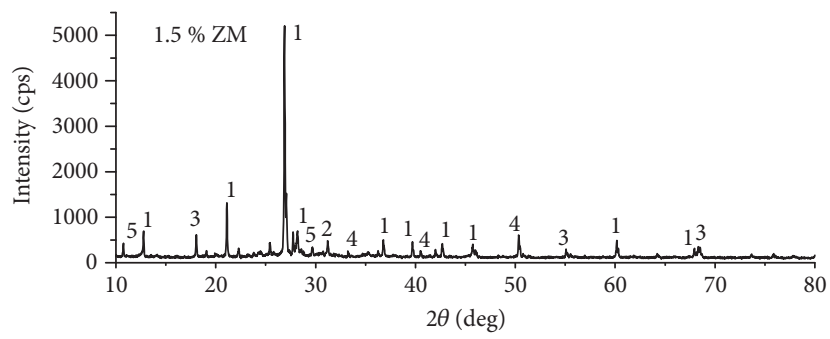

(b)

FIGURE 8: X-ray diffraction results for specimens with different ZM concentrations after seven days of curing: (a) $0 \% \mathrm{ZM}$ and (b) $1.5 \% \mathrm{ZM}$.

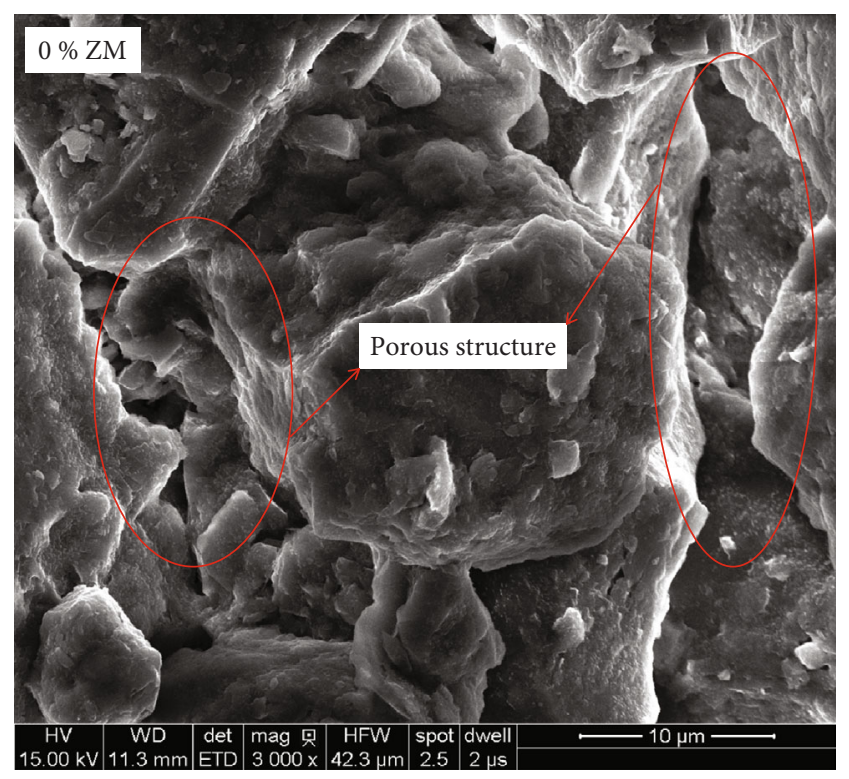

FIGURE 9: Micrograph of saline soils with $0 \% \mathrm{ZM}$ after seven days of curing.

results, $\mathrm{ZM}$ is a new type of aqueous polymer soil stabilizer, which effectively stabilizes saline soil.

The test results show that ZM-modified soils have higher strength than unmodified soils. Additionally, it was observed that the UCS of ZM-modified soils increases with increasing $\mathrm{ZM}$ concentration and curing time and decreases with increasing salt content.

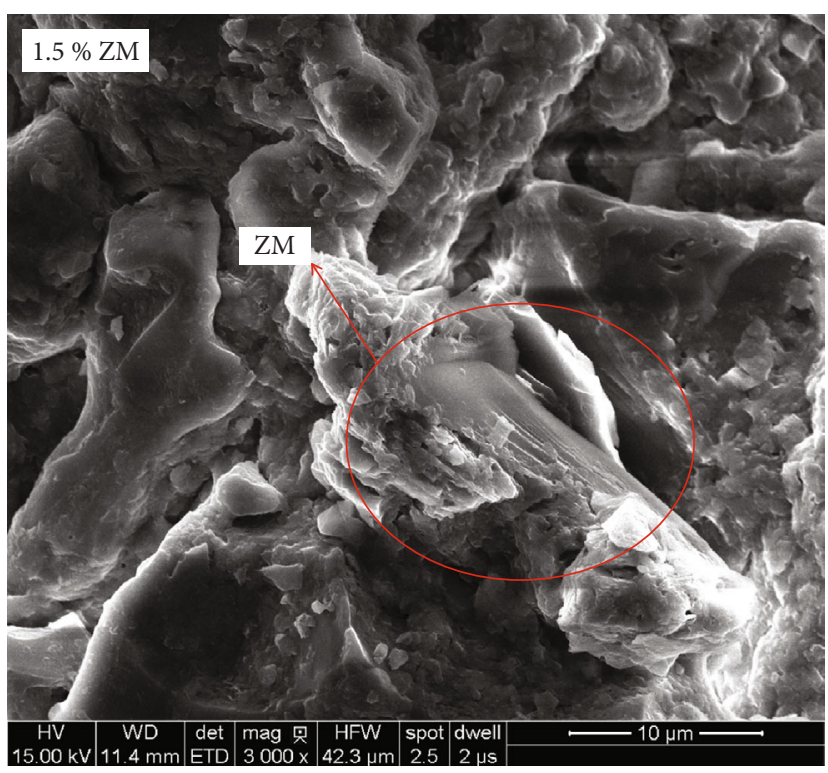

(a)

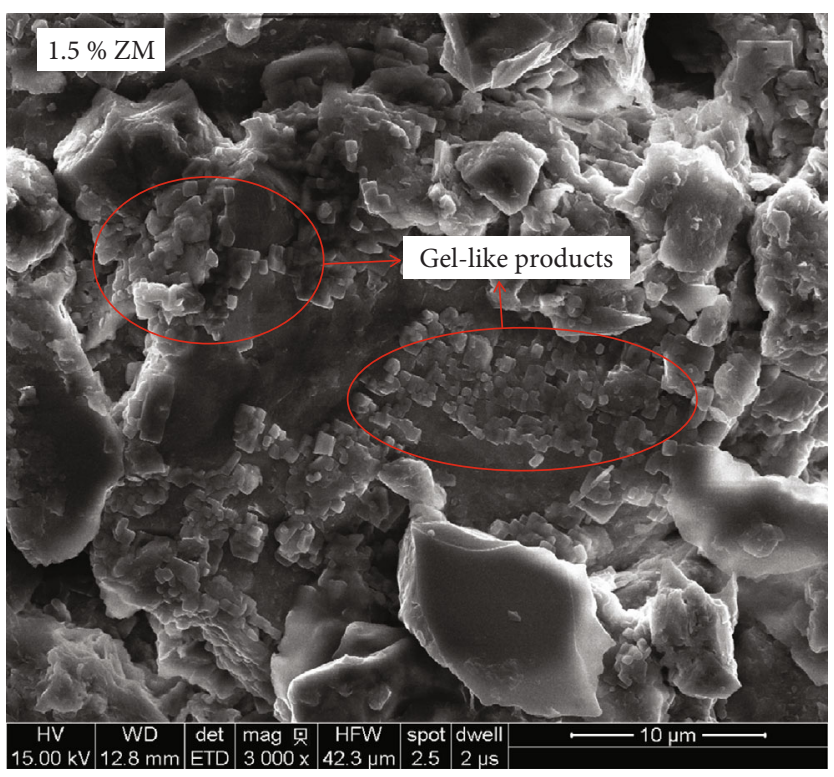

(b)

Figure 10: SEM images of saline soils modified with $1.5 \% \mathrm{ZM}$ after (a) $7 \mathrm{~d}$ and (b) $28 \mathrm{~d}$ of curing.

Moreover, the water stability and wetting-drying cycling resistance significantly improve with increasing ZM concentration and curing time.

Based on the UCS, water stability, and wetting-drying cycling resistance test results, $1.5 \% \mathrm{ZM}$ can be regarded as an optimum concentration for yielding an effective stabilization.

Although the X-ray diffraction results indicate no new functional groups or mineral components, SEM clearly shows the membrane structure of ZM-modified saline soil. The newly formed gel-like material fills the voids in the soil and covers the particle surfaces in a form of a viscous membrane structure. This phenomenon leads to the strength increase. 


\section{Data Availability}

The data used to support the findings of this study are available from the corresponding author upon request.

\section{Conflicts of Interest}

No potential conflict of interest is reported by the authors.

\section{Acknowledgments}

This research is financially supported by the National Natural Science Foundation of China (Grant No. 51508159) and by the Natural Science Foundation of Jiangsu Province of China (Grant No. BK20130832). The authors gratefully acknowledge Prof. Qunfeng Ma, Dr. Yafeng Yao, and Engineer Honghua Dai from the School of Architectural Engineering Institute, Nantong Vocational University, China, for their contribution to the laboratory tests.

\section{Supplementary Materials}

Figure S1: synthesis reaction device of ZM. Figure S2: prepared specimens. Figure S3: specimens with different ZM concentrations after a curing time of seven days and 24-hour immersion: (a) 0\% ZM, (b) $0.9 \% \mathrm{ZM}$, and (c) $1.5 \%$ ZM. Figure S4: specimens with different ZM concentrations after a curing time of 28 days and 1 wetting-drying cycle: (a) $0 \% \mathrm{ZM}$, (b) $0.9 \% \mathrm{ZM}$, and (c) $1.5 \%$ ZM. (Supplementary Materials)

\section{References}

[1] X. Zhao, A. Shen, Y. Guo, P. Li, and Z. Lv, "Pavement mechanic response of sulfate saline soil subgrade section based on fluid-structure interaction model," International Journal of Pavement Research and Technology, vol. 10, no. 6, pp. 497-506, 2017.

[2] Z. Y. Cai, Z. Q. Wu, Y. H. Huang, and Y. B. Wei, "Salt-frost heave properties of channel bed soil in the Northern Xinjiang," Journal of Hydraulic Engineering, vol. 47, no. 7, pp. 900-906, 2016.

[3] L. Wei, S. Chai, H. Cai, and M. Li, "Triaxial shear strength and deviatoric stress-strain of saline soils reinforced with wheat straws," Chinese Civil Engineering Journal, vol. 45, no. 1, pp. 109-114, 2012.

[4] N. Zia and P. J. Fox, "Engineering properties of loess-fly ash mixtures for roadbase construction," Transportation Research Record: Journal of the Transportation Research Board, vol. 1714, no. 1, pp. 49-56, 2000.

[5] R. Ziaie-Moayed, M. Samimifar, and M. Kamalzare, "Improvement of shear strength characteristics of saline soil using cement and polymer," International Journal of Geotechnical Engineering, vol. 5, no. 3, pp. 307-314, 2011.

[6] Z. Yu, L. Jian-Kun, F. Jian-Hong, and X. An-Hua, "Reinforcement effects of ground treatment with dynamic compaction replacement in cold and saline soil regions," Sciences in Cold and Arid Regions, vol. 5, no. 4, pp. 440-443, 2013.

[7] M. Chai, H. Zhang, J. Zhang, and Z. Zhang, "Effect of cement additives on unconfined compressive strength of warm and ice- rich frozen soil," Construction and Building Materials, vol. 149, pp. 861-868, 2017.

[8] S. Horpibulsuk, R. Rachan, A. Chinkulkijniwat, Y. Raksachon, and A. Suddeepong, "Analysis of strength development in cement-stabilized silty clay from microstructural considerations," Construction and Building Materials, vol. 24, no. 10, pp. 2011-2021, 2010.

[9] T. Kamei, A. Ahmed, and K. Ugai, "Durability of soft clay soil stabilized with recycled bassanite and furnace cement mixtures," Soils and Foundations, vol. 53, no. 1, pp. 155-165, 2013.

[10] Z. Wu, Y. Deng, S. Liu, Q. Liu, Y. Chen, and F. Zha, "Strength and micro-structure evolution of compacted soils modified by admixtures of cement and metakaolin," Applied Clay Science, vol. 127-128, pp. 44-51, 2016.

[11] N. Latifi, A. Marto, A. S. A. Rashid, and J. L. J. Yii, "Strength and physico-chemical characteristics of fly ash-bottom ash mixture," Arabian Journal for Science and Engineering, vol. 40, no. 9, pp. 2447-2455, 2015.

[12] P. Sukmak, S. Horpibulsuk, S. L. Shen, P. Chindaprasirt, and C. Suksiripattanapong, "Factors influencing strength development in clay-fly ash geopolymer," Construction and Building Materials, vol. 47, pp. 1125-1136, 2013.

[13] S. Horpibulsuk, R. Rachan, and Y. Raksachon, "Role of fly ash on strength and microstructure development in blended cement stabilized silty clay," Soils and Foundations, vol. 49, no. 1, pp. 85-98, 2009.

[14] A. A. Al-Rawas, A. W. Hago, and H. Al-Sarmi, "Effect of lime, cement and Sarooj (artificial pozzolan) on the swelling potential of an expansive soil from Oman," Building and Environment, vol. 40, no. 5, pp. 681-687, 2005.

[15] Y. Guney, D. Sari, M. Cetin, and M. Tuncan, "Impact of cyclic wetting-drying on swelling behavior of lime-stabilized soil," Building and Environment, vol. 42, no. 2, pp. 681-688, 2005.

[16] B. R. Phanikumar and R. Singla, "Swell-consolidation characteristics of fibre-reinforced expansive soils," Soils and Foundations, vol. 56, no. 1, pp. 138-143, 2016.

[17] M. Ayeldeen and M. Kitazume, "Using fiber and liquid polymer to improve the behaviour of cement-stabilized soft clay," Geotextiles and Geomembranes, vol. 45, no. 6, pp. 592-602, 2017.

[18] M. Mirzababaei, M. Miraftab, M. Mohamed, and P. McMahon, "Unconfined compression strength of reinforced clays with carpet waste fibers," Journal of Geotechnical and Geoenvironmental Engineering, vol. 139, no. 3, pp. 483493, 2013.

[19] N. M. Al-Akhras, M. F. Attom, K. M. Al-Akhras, and A. I. H. Malkawi, "Influence of fibers on swelling properties of clayey soil," Geosynthetics International, vol. 15, no. 4, pp. 304-309, 2008.

[20] F. Yazdandoust and S. S. Yasrobi, "Effect of cyclic wetting and drying on swelling behavior of polymer-stabilized expansive clays," Applied Clay Science, vol. 50, no. 4, pp. 461-468, 2010.

[21] H. I. Inyang and S. Bae, "Polyacrylamide sorption opportunity on interlayer and external pore surfaces of contaminant barrier clays," Chemosphere, vol. 58, no. 1, pp. 19-31, 2005.

[22] N. Latifi, A. S. A. Rashid, S. Siddiqua, and M. Z. A. Majid, "Strength measurement and textural characteristics of tropical residual soil stabilised with liquid polymer," Measurement, vol. 91, pp. 46-54, 2016. 
[23] J. Liu, B. Shi, H. Jiang, S. Bae, and H. Huang, "Improvement of water-stability of clay aggregates admixed with aqueous polymer soil stabilizers," Catena, vol. 77, no. 3, pp. 175-179, 2009.

[24] J. Liu, B. Shi, H. Jiang, H. Huang, G. Wang, and T. Kamai, "Research on the stabilization treatment of clay slope topsoil by organic polymer soil stabilizer," Engineering Geology, vol. 117, no. 1-2, pp. 114-120, 2011.

[25] J. Liu, G. Wang, T. Kamai, F. Zhang, J. Yang, and B. Shi, "Static liquefaction behavior of saturated fiber-reinforced sand in undrained ring-shear tests," Geotextiles and Geomembranes, vol. 29, no. 5, pp. 462-471, 2011.

[26] S. A. Naeini, B. Naderinia, and E. Izadi, "Unconfined compressive strength of clayey soils stabilized with waterborne polymer," KSCE Journal of Civil Engineering, vol. 16, no. 6, pp. 943-949, 2012.

[27] S. S. Kukal, M. Kaur, S. S. Bawa, and N. Gupta, "Water-drop stability of PVA-treated natural soil aggregates from different land uses," Catena, vol. 70, no. 3, pp. 475-479, 2007.

[28] Z. D. Zhu and S. Y. Liu, "Utilization of a new soil stabilizer for silt subgrade," Engineering Geology, vol. 97, no. 3-4, pp. 192198, 2008.

[29] G. Ma, F. Ran, E. Feng, Z. Dong, and Z. Lei, "Effectiveness of an eco-friendly polymer composite sand-fixing agent on sand fixation," Water, Air, \& Soil Pollution, vol. 226, no. 7, article 2490, pp. 1-2, 2015.

[30] J. Liu, Q. Feng, Y. Wang, D. Zhang, J. Wei, and D. P. Kanungo, "Experimental study on unconfined compressive strength of organic polymer reinforced sand," International Journal of Polymer Science, vol. 2018, Article ID 3503415, 18 pages, 2018.

[31] J. Liu, Z. Song, Y. Bai et al., "Laboratory tests on effectiveness of environment-friendly organic polymer on physical properties of sand," International Journal of Polymer Science, vol. 2018, Article ID 5865247, 11 pages, 2018.

[32] M. A. Mohsin and N. F. Attia, "Inverse emulsion polymerization for the synthesis of high molecular weight polyacrylamide and its application as sand stabilizer," International Journal of Polymer Science, vol. 2015, Article ID 436583, 10 pages, 2015.

[33] S. Onyejekwe and G. S. Ghataora, "Soil stabilization using proprietary liquid chemical stabilizers: sulphonated oil and a polymer," Bulletin of Engineering Geology and the Environment, vol. 74, no. 2, pp. 651-665, 2015.

[34] ASTM D698-12e2, Standard Test Methods for Laboratory Compaction Characteristics of Soil Using Standard Effort (12 $\left.400 \mathrm{ft}-\mathrm{lbf} / \mathrm{ft}^{3}\left(600 \mathrm{kN}-\mathrm{m} / \mathrm{m}^{3}\right)\right)$, ASTM, West Conshohocken, PA, USA, 2012.

[35] ASTM D2166/D2166M-16, Standard Test Method for Unconfined Compressive Strength of Cohesive Soil, ASTM, West Conshohocken, PA, USA, 2016.

[36] ASTM D4609-08, Standard Guide for Evaluating Effectiveness of Admixtures for Soil Stabilization (Withdrawn 2017), ASTM, West Conshohocken, PA, USA, 2008. 


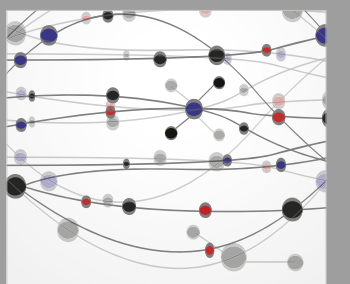

The Scientific World Journal
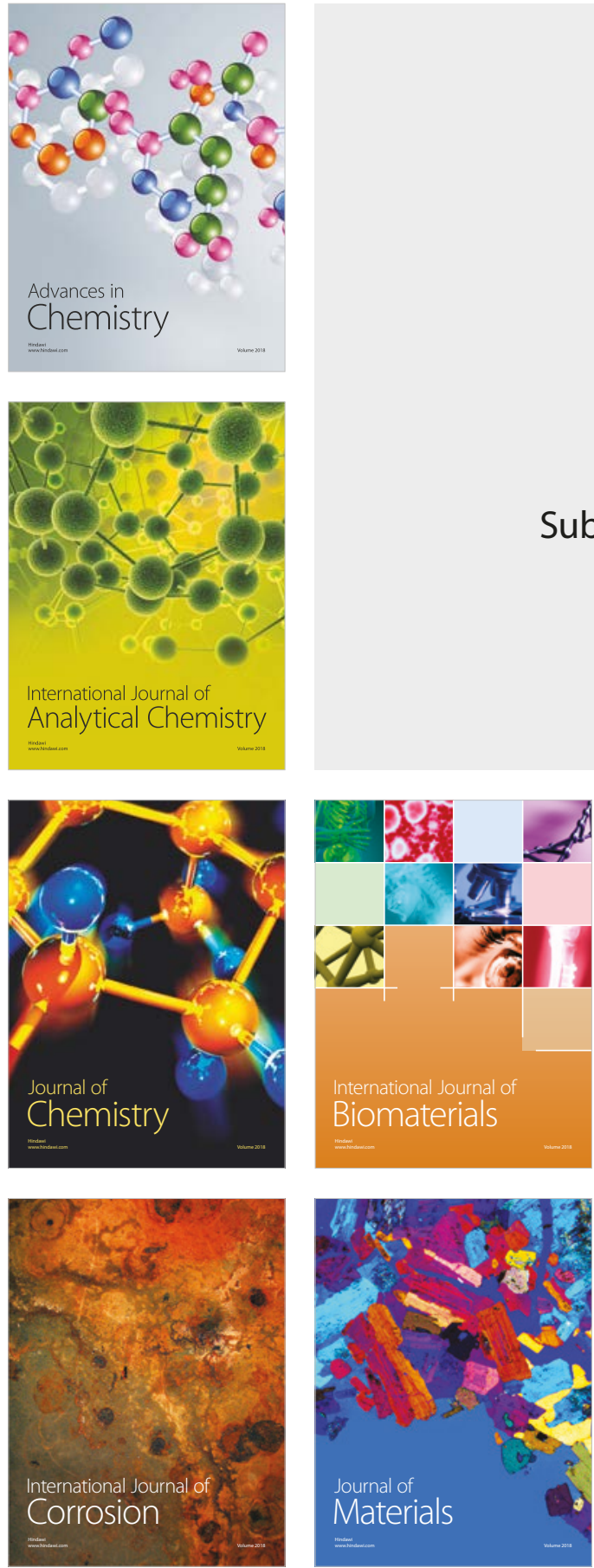

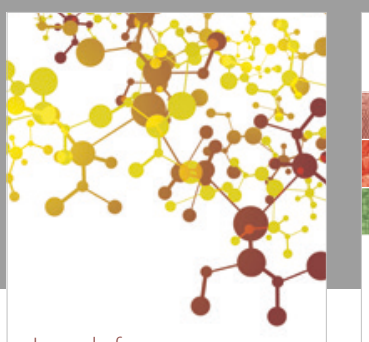

Journal of

Applied Chemistry
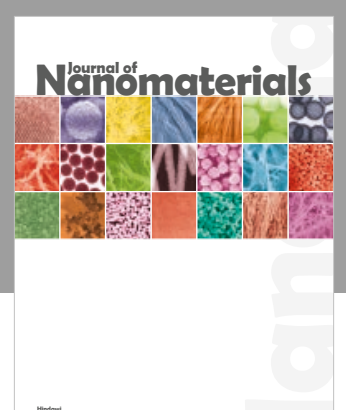

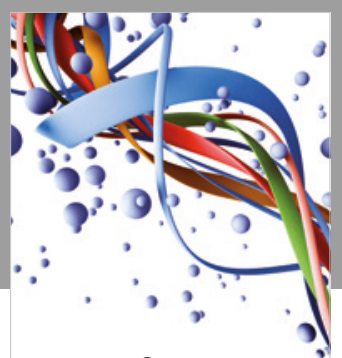

Scientifica

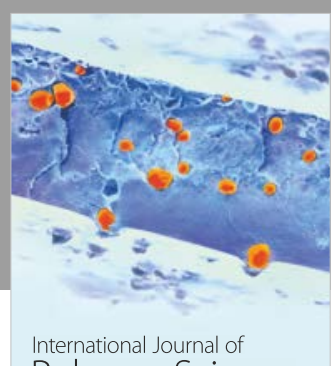

Polymer Science

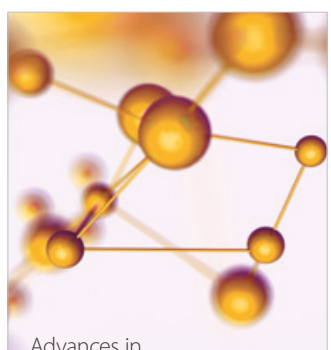

Physical Chemistry
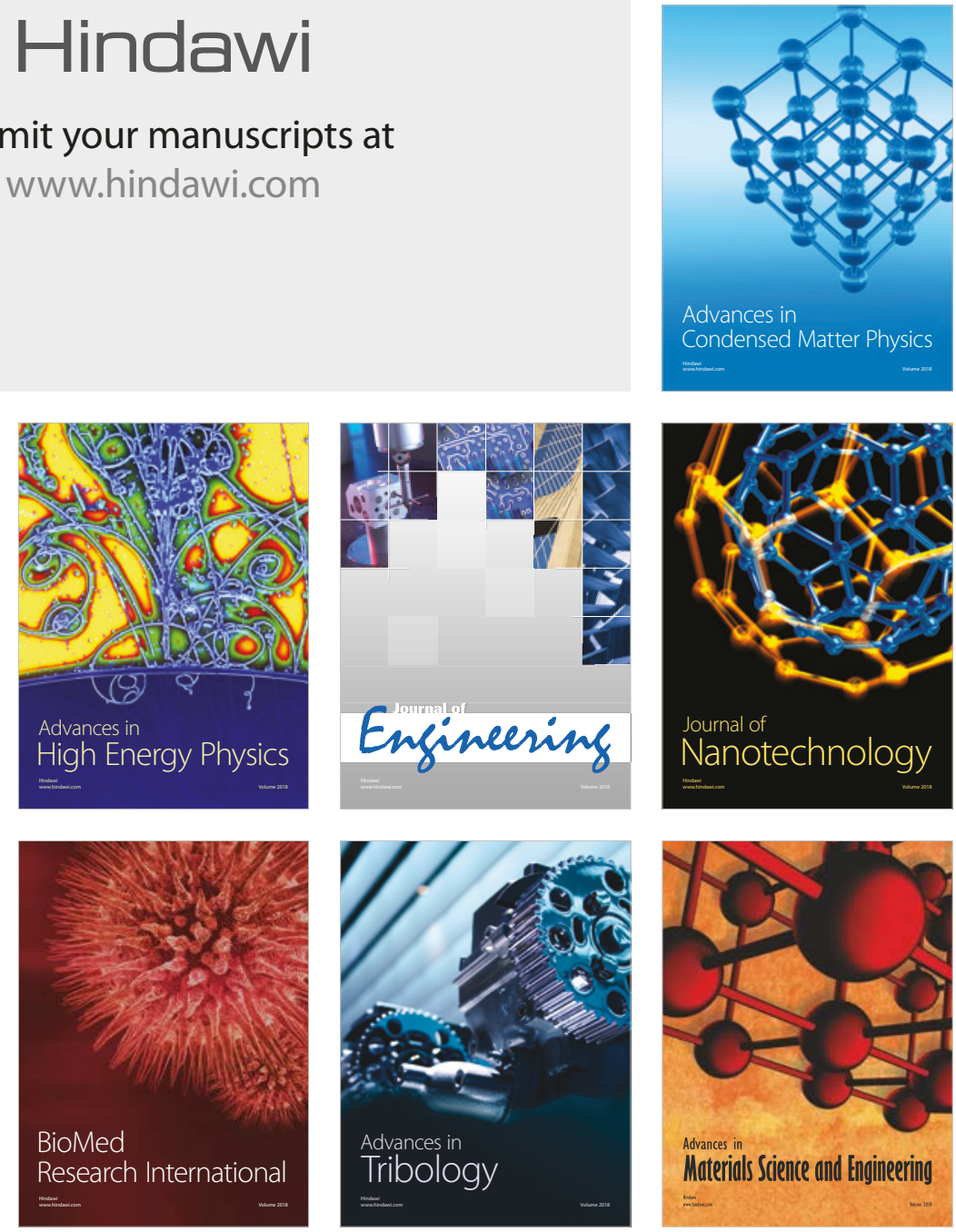